\title{
Sudanese Perspectives on Resettlement in Australia
}

\author{
Kate E. Murray \\ San Diego State University/University of California San Diego*, USA
}

\begin{abstract}
$R^{\mathrm{es}}$ esettlement programs for people from a refugee background must respond to a variety of concerns as people from diverse backgrounds and often longstanding periods of upheaval and hardship enter their new resettlement communities. Host countries approach the demands of resettlement through varying programs and policies and those differences across countries can profoundly affect the newcomers' experiences. The current study employs quantitative and qualitative methods to examine the individual and contextual factors that influence the resettlement experience for adults from Sudan being resettled in Queensland, Australia. Ninety Sudanese adults were recruited through snowball sampling techniques for the quantitative study, with 10 individuals purposefully selected to complete the semistructured qualitative interview. In the quantitative sample, 25 to $30 \%$ of participants reported significant symptoms of psychological distress and frequent experiences of discrimination, and the majority of participants reported integration (identifying with both Australian and Sudanese cultures) as their method of acculturation. Participants reported feeling initially welcomed into Australia, with positive influences including bonding and bridging capital, which helped them in their adaptation, and negative influences including problems with the resettlement programs and experiences of discrimination. The findings underscore the importance of sociopolitical context on refugee experiences of the resettlement process.
\end{abstract}

Keywords: refugee settlement, Sudanese, Australia, mixed methods

In 2007, 67 million people were identified by the United Nations High Commissioner for Refugees (UNHCR) as persons of concern; representing a significant number of people suffering from persecution and including groups, such as refugees, asylum seekers and people who are internally displaced within their own country (UNHCR, 2008a). Refugees, as defined by the 1951 United Nations Convention Relating to the Status of Refugees, are individuals who have crossed an international boundary and are unable or unwilling to return home for fear of persecution for one of five reasons, including: race, religion, nationality, membership of a particular social group, or political opinion (Article 1). The 1951 convention and subsequent 1967 protocol outline the responsibilities of countries who have signed the convention and protocol (approximately 150 worldwide) to provide protection for those seeking asylum; however, the convention does not apply to those countries that have not ratified the protocol or for individuals who are internally displaced. Asylum seekers, also referred to as refugee claimants, are individuals who arrive in another country without proper documentation or visas and may face additional hardship as they seek safety and protection in a country of first asylum (see Davidson, Murray, \& Schweitzer, 2008 for a review).

The UNHCR outlines three durable solutions for refugees: repatriation, integration into the country of first asylum, and third country resettlement. Very few refugees $(<1 \%)$ enter into resettlement programs in the nine traditional resettlement countries. In resettlement, people from a refugee background must cope with their past traumas and flight experiences as well as the demands of relocation to distant and diverse parts of the world, where they are frequently separated from family and familiar ways of life. Resettlement countries vary in the extent to which they address the range of social, cultural, linguistic and financial concerns through their federal humanitarian programs and the Australian offshore humanitarian program has been touted as one of the most generous in the world as it incorporates a wide range of programs

Address for correspondence: Kate E. Murray, San Diego State University/University of California San Diego*, Cancer Center Partnership, 6363 Alvarado Court, MC 1895, San Diego, CA 92120-4913, USA.E-mail: kmurray@projects.sdsu.edu 
over an extended period of time. However, Australia has been criticised for other immigration policies, including the detention of asylum seekers, and resettlement countries as a whole support a very small number of refugees. On the other hand, $66 \%$ of all refugees are being supported by poor and developing countries and $30 \%$ are supported by the world's 49 least-developed countries (UNHCR, 2003), clearly highlighting imbalance in the provision of resources and support to address this international concern. Resettlement programs continue to evolve as they respond to national and international attitudes towards migration and the increasing pressures from international bodies for more equitable sharing of responsibilities to protect refugees.

The Republic of Sudan was the third largest generator of refugees in 2007 (UNHCR, 2008b), with over 1.6 million Sudanese persons of concern (UNHCR, 2007) and millions killed and displaced in Southern Sudan and the Darfur region over the past 50 years of civil war. To date, instability persists in Sudan, geographically the largest and among the most ethnically diverse countries in Africa (Metz, 1991). Given the longstanding nature of Sudanese conflict, there are wide-ranging experiences among diverse Sudanese nationals scattered around the world as the country continues to struggle to establish safety and peace and begin the process of rebuilding. More than 20,000 Sudanese refugees have been resettled in Australia since 1996 (Department of Immigration and Citizenship [DIAC], 2007a), representing a significant proportion of the country's humanitarian program in the last several years.

There has been a growing body of research with Sudanese populations over the past 10 years (see Tempany, 2009 for a review), with the majority of the research focusing on a specific group of Sudanese, youth and unaccompanied minors who are frequently referred to as the Lost Boys of Sudan. Research has shown extensive experiences of prior torture and trauma among Sudanese refugees (Paardekooper, deJong, \& Hermanns, 1999; Schweitzer, Melville, Steel, \& Lacherez, 2006) and that prior trauma (Schweitzer et al., 2006) and postmigration challenges are significant predictors of greater symptoms of psychological distress (Schweitzer et al., 2006; Simich, Hamilton, \& Baya, 2006). However, the literature also underscores the resilience of the Sudanese community and the importance of social support and social connections for health and wellbeing (Schweitzer, Greenslade, \& Kagee, 2007; Tankik \& Richters, 2006); this highlights the potentially potent influence of social context on the experiences of Sudanese in resettlement.

Debates over resettlement programs and policies are apparent worldwide (e.g. Gorman, 1991; Marsella, Bornemann, Ekblad, \& Orley, 1994; McDougall, 1991) and in the last several years the Sudanese community has been highlighted within Australian public debate. In 2007, during the period of data collection for the current study, an announcement was made that the Sudanese component of the humanitarian resettlement program would be temporarily halted and significantly reduced for the next year. In announcing this change the Minister of Immigration stated,

Some groups don't seem to be settling and adjusting to the Australian way of life as quickly as we would hope, and therefore it makes sense to ... slow down the rate of intake from countries such as Sudan. (as cited in Hart \& Maiden, 2007, para. 7)

Integration is increasingly cited as a goal for resettlement programs, and host countries develop their programs and policies according to community beliefs about multiculturalism and migration (Ager \& Strang, 2008). Ager and Strang (2008) reviewed definitions of integration and identified four primary emphases across definitions: access to and obtaining employment, housing, education and health; achieving citizenship and rights; social connections within and across cultures; and overcoming structural barriers related to language, culture and community environment. These domains underscore the importance of refugees having opportunities to engage with their new community and meet their daily needs. However, integration does not preclude the maintenance of one's cultural heritage and ways of life; widely used definitions of acculturation define integration as identifying with both one's new and native cultures (Berry, 1994). Furthermore, it is essential to recognise that an emphasis on integration potential does not necessarily correspond with repeated calls by the UN to provide resettlement to those with the greatest safety and health needs (Browne, 2007). Integration may be a goal for resettlement programs; however, it should not be a primary focus of the selection process if the primary goals of safety outlined by the UN are maintained.

The sociopolitical context can greatly influence the experiences of refugees in resettlement. The current study employs quantitative and qualitative methods to examine issues of integration and the influences of community context on the experiences of Sudanese adults in Australia. In particular, it examines community factors such as the experiences of discrimination and social ties within the Sudanese community (also referred to as bonding capital) and between Sudanese and other Australians (bridging capital; Putnam, 2000). Moreover, the quantitative data provide opportunities to examine and compare key outcome variables previously assessed with other refugee groups. The qualitative data provide a descriptive overlay to enhance understanding of the resettlement experience and definitions of positive outcomes in resettlement from the perspective of Sudanese adults in Brisbane. The use of mixed methods provides the opportunity for triangulation to compare and contrast findings across different methodologies. 


\section{Method \\ Sample}

At the start, contact was made with community leaders such as elders in the community and leaders in Sudanese community organisations to seek approval and support for the project. These leaders facilitated connections with community members through informal introductions, allowing the researchers to present at community meetings and through e-mail distribution lists. Three interpreters (two females and one male), who had worked extensively as interpreters for the community, were recruited to the research team to assist with recruitment and the implementation of study materials into Sudanese Arabic and Dinka, in addition to English. Participants were recruited by providing information regarding the study at community gatherings, through a Sudanese community organisation, and at English as a Second Language courses and enrolling interested participants in the greater Brisbane region between June and December 2007. Sudanese adults were recruited to complete the quantitative questionnaire, with a total of 90 adults (56 women and 34 men) with a mean age of 34.19 years $(S D=9.37)$ participating in the quantitative study. These individuals represented 20 different ethnic groups who entered Australia an average 3.45 years prior $(S D=2.09)$ through the federal humanitarian program and the majority of participants identified as Christian $(n=51,56.6 \%)$. On average, participants had completed between 6 and 12 years of education and 50.6\% $(n=44)$ of the sample was unemployed at the time of their participation. Table 1 provides additional demographic details for the quantitative sample.

For the qualitative interview, a diverse group of individuals were purposefully sampled across age $(M=$

\section{Table 1}

Demographics for Total Sample

\begin{tabular}{lcc}
\hline & Mean/Number & SD/\% \\
\hline Marital Status & & \\
$\quad$ Married/partnered & 56 & $62.2 \%$ \\
$\quad$ Single/never married & 21 & $23.3 \%$ \\
$\quad$ Divorced, separated, or widowed & 13 & $14.4 \%$ \\
Average Years in Australia & 3.45 & 2.09 \\
Employment Status & & \\
$\quad$ Unemployed & 44 & $50.6 \%$ \\
$\quad$ Part-time employment (1-20 hours) & 13 & $14.9 \%$ \\
$\quad$ Full-time employment (21+ hours) & 31 & $35.6 \%$ \\
Average Income & 2.99 (\$25-30,000) \\
Average Education (In Sudan) & 3.49 & 1.11 \\
& $(3=6+$ years; & \\
& $4=\mathrm{HS} \mathrm{diploma)}$ & \\
Religious Identification & & 56.73 \\
Christian & 51 & $37.8 \%$ \\
Muslim & 34 & $4.4 \%$ \\
Other & 4.54 & \\
Number of Traumatic Events & & \\
\hline
\end{tabular}

36.50, $S D=8.06$ ) and gender ( 5 females and 5 males) until 10 individuals with strong English language skills participated in the individual, semistructured interviews. Half $(n=5)$ of the participants came to Australia from refugee camps in Africa while four entered through countries of first asylum, such as Nairobi, Kenya or Cairo, Egypt; one participant left directly from Sudan. Each qualitative participant also elected to complete the quantitative questionnaire and, on average, the qualitative participants reported significantly higher levels of education (all had completed at least secondary education), higher levels of prior trauma ( $M=7.9$ traumatic events, $S D=5.28)$, and having spent more time in Australia $(M=5.2$ years, $S D=2.66)$ than the average of the quantitative participants. In the current study, pseudonyms were used and identifying information was removed in order to ensure confidentiality.

\section{Measures}

A battery of items was compiled and took approximately 60 minutes to complete. Items assessed basic demographic data and access, utilisation and satisfaction with a range of services provided in resettlement. Experiences of everyday discrimination (Essed, 1991) were assessed by 9 items (e.g., 'people act as if you are not smart' and 'you are called names or insulted') on a 6-point scale of how frequently specific things had happened in their day-to-day life ( $0=$ never to $5=$ happens almost every day). Symptoms of posttraumatic stress disorder (PTSD) and history of traumatic events were assessed by the Harvard Trauma Questionnaire (HTQ) and symptoms of anxiety, depression and somatisation were assessed by the Hopkins Symptoms Checklist-25 (HSCL); both developed and validated with refugee samples (Mollica, Wyshak, de Marneffe, Khuon, \& Lavelle, 1987). Traumatic events were further divided into 11 items assessing events related to threat to physical integrity (e.g., torture) and five items assessing loss events (e.g., family/friend killed). These subscales were developed based on content, as opposed to factor analysis, and exhibited high internal consistency.

A measure of subjective wellbeing was adapted from other research (Adler, Epel, Castellazzo, \& Ickovics, 2000) and used to assess refugees' perceptions of their wellbeing as compared to others in their own ethnic community and members of the larger Australian community. Participants were asked to mark an $\mathrm{X}$ on a ladder representing their own status on a scale ranging from 1 to 10, where a score of 10 represents people who are have the highest levels of wellbeing in the community and a score of 1 represents people who have the lowest levels of wellbeing in the community.

A 21-item measure of acculturation (adapted from Zea, Asner-Self, Birman, \& Buki, 2003) measured three subscales of acculturation to both Australian and Sudanese culture, including: cultural identity (e.g., 
'I have a strong sense of being Australian/Sudanese'), language competence (e.g., 'How well do you speak English at school or work?') and cultural competence (e.g., 'How well do you know Australian/Sudanese politicians?'). The measure was scored so that positive ratings on the 4-point Likert scale represented preference for a stated culture and negative scores represented lack of acculturation (e.g., not speaking the language or not identifying with the culture). A total score was calculated by summing scores on the three subscales for each Australian and Sudanese cultures and categorising each participant as integrated, assimilated, separated or marginalised based on Berry's (1994) model of acculturation. Table 2 provides a visual representation of the model. A continuous variable was also calculated to represent participant level of multiculturalism by multiplying scores of Sudanese and Australian acculturation, in which positive scores indicate a preference for the stated culture (Rudmin, 2006). A positive product score indicates biculturalism since no participants reported marginalisation in the current study, which would also result in a positive product score by multiplying two negative ratings. A negative product score indicates uniculturalism, identifying with either Sudanese or Australian culture singly.

The semistructured qualitative interviews, approximately 60 minutes in length, led participants through a series of questions asking them to describe their initial experiences in resettlement, positive and negative factors influencing their adaptation to life in Australia, and definitions of 'the good life' in order to tap Sudanese perspectives on successful outcomes in resettlement. All interviews were based upon narrative approaches (McAdams, 2006) and conducted by the author and introducing, follow-up and probing questions followed recommendations for interviewing techniques in qualitative analyses (Kvale, 1996). Transcriptions were made of the interviews with the support of two research assistants.

\section{Data Analyses}

All quantitative statistical analyses were conducted using SPSS $^{\circledR}$ (version 12.0). Data were examined to identify errors in data entry and to determine whether key study variables adhered to normal distributions, including

\section{Table 2}

Levels of Acculturation

\begin{tabular}{|c|c|c|c|}
\hline \multicolumn{2}{|c|}{$\begin{array}{l}\text { Strategies of the } \\
\text { Ethnocultural Groups }\end{array}$} & \multicolumn{2}{|c|}{$\begin{array}{l}\text { Maintenance of heritage, } \\
\text { culture and identity }\end{array}$} \\
\hline & & High & Low \\
\hline \multirow{5}{*}{$\begin{array}{l}\text { Relationships } \\
\text { Sought among } \\
\text { Groups }\end{array}$} & High & Integration & Assimilation \\
\hline & & $54.4 \%(n=49)$ & $1.1 \%(n=1)$ \\
\hline & & & \\
\hline & Low & Separation & Marginalisation \\
\hline & & $40 \%(n=36)$ & $0 \%$ \\
\hline
\end{tabular}

Note: Adapted from Berry, 1994. assessment of skew and kurtosis, and multi-item internal consistency. The qualitative interviews were analysed using Miles and Huberman's systematic approach to qualitative data (Huberman \& Miles, 1994; Miles \& Huberman, 1994). A systematic approach was used to explore specific themes related to adaptation and positive and negative experiences in resettlement. The data were coded by using a variable-oriented approach to examine specific questions from the interviews to identify themes across participants. In accordance with systematic methods, the research began with specific questions already developed, and then proceeded through the steps of (1) data reduction, (2) data display, and (3) conclusion drawing and confirmation (Morrow \& Smith, 2000). These steps were done by the author in consultation with a colleague (DN) to review key themes, data display and conclusions during data analysis.

\section{Results}

The key aims of the study include: to compare and contrast mental health outcomes with research with other refugee groups, to enhance understanding of issues of acculturation and the challenges of resettlement, to explore the influences of community and resettlement program factors and to obtain Sudanese perspectives on the Australian settlement experience. First, the quantitative analyses will be presented; then, as the qualitative findings are offered triangulation across the two methods will be presented.

\section{Initial Quantitative Analyses}

Key study variables were examined to determine whether they adhered to normal distributions, including assessment of skew and kurtosis, and multi-item internal consistency. Two items in the Life Satisfaction scale were identified as non-normal ( $k$ kew $>2$ ), and internal consistency for multi-item scales was satisfactory, including consistency ratings for the total PTSD score on the HTQ (Cronbach's alpha $=.902)$, total score of psychological distress on the HSCL (Cronbach's alpha $=.917$ ), threat to physical integrity subscale on the HTQ (Cronbach's alpha $=.802)$ and traumatic loss subscale on the HTQ (Cronbach's alpha $=.764)$. Two subscales on the AMAS had Cronbach's alpha coefficients below the recommended standard of .7, including knowledge of Sudanese culture on the AMAS (Cronbach's alpha = .597), total Sudanese acculturation on the AMAS (Cronbach's alpha $=.508)$ and altering the items included in these subscales was unsuccessful in increasing the reliability.

\section{Main Quantitative Findings}

Trauma and mental health outcomes. Overall, participants reported an average 5.54 trauma experiences $(S D=$ $4.16)$ and $38.6 \%$ of the participants reported experiences of torture. Higher levels of traumatic events were not 
correlated with age or gender. Individuals who had spent time in a refugee camp (coded as 1) reported higher levels of prior trauma than those who had not $(r=.266$, $p<.05$ ). Christians (coded as 1 ) reported higher levels of trauma than individuals who identified as Muslim $(r=$ $.307, p<.01)$. Twenty-five individuals $(29 \%)$ reported significant psychological distress on the HSCL $(M=1.55$; $S D=0.48$ ) by meeting recommended cut-off scores $(>1.75)$ on the HSCL total score. Twenty participants (21\%) reported significant symptoms of PTSD on the HTQ $(M=1.62 ; S D=0.56)$ by meeting recommended cut-off scores $(\geq 2.00)$ for PTSD on the scale. The mean scores for the current sample are similar to reported HSCL and HTQ in other studies with refugee populations (e.g., Lie, 2002; Schweitzer et al., 2006). Younger adults reported higher levels of symptoms of PTSD $(r=-$ $.231, p<.05)$ and total symptomatology measured by the HSCL $(r=-.254, p<.05)$, and individuals who had spent time in a refugee camp reported greater symptoms of PTSD $(r=.234, p<.05)$. Table 3 provides an overview of correlations between key study variables.

Regression analyses revealed higher rates of prior trauma predicted greater symptoms of PTSD and HSCL when controlling for age. Table 4 provides data from hierarchical regression analyses. This supports previous research findings suggesting that with increased exposure to trauma there are elevations in reports of psychological distress (Carlson \& Rosser-Hogan, 1991; Kinzie et al., 1990). Furthermore, loss-related events was a significant predictor of HSCL symptoms of distress and was not a significant predictor of symptoms of $\operatorname{PTSD}(p=.772)$.

Participants were asked to rank themselves on a 10 -point scale to represent their level of subjective wellbeing, first, in comparison to others in the Sudanese
Table 4

Hierarchical Regression Predicting Mental Health Outcomes

\begin{tabular}{lcccccc}
\hline Effect & B & SE B & $\beta$ & Step $R^{2}$ & $R^{2}$ change & $F$ change $(d f)$ \\
\hline Predicting & & & & & & \\
PTSD \\
total score
\end{tabular}

community and, second, to others in the larger Australian community. Overall, participants rated themselves significantly higher in subjective wellbeing ( $t=10.23, p<.001)$ when comparing themselves to others in the Sudanese community $(M=5.94, S D=$ 2.81) than when comparing themselves to others within the larger Australian community $(M=3.83, S D=2.60)$. This finding suggests a significant loss of perceived wellbeing within the new host Australian community. As compared to members of the Australian community, subjective wellbeing was significantly correlated with education $(r=.438, p<.01)$, income $(r=.257, p<.05)$,

\section{Table 3}

Correlations Between Study Variables

\begin{tabular}{|c|c|c|c|c|c|c|c|c|c|c|c|c|c|c|}
\hline Variable & 1 & 2 & 3 & 4 & 5 & 6 & 7 & 8 & 9 & 10 & 11 & 12 & 13 & 14 \\
\hline 1. Age & - & & & & & & & & & & & & & \\
\hline 2. Gender & $-.23^{*}$ & - & & & & & & & & & & & & \\
\hline 3. Education & $.23^{*}$ & .09 & - & & & & & & & & & & & \\
\hline 4. Income & $.34^{* *}$ & -.14 & .18 & - & & & & & & & & & & \\
\hline 5. Years in Aus & .16 & .07 & $.44^{* *}$ & .07 & - & & & & & & & & & \\
\hline 6. Camp & $-.21^{*}$ & .18 & .03 & $-.25^{*}$ & -.05 & - & & & & & & & & \\
\hline 7. Trauma events & -.06 & -.13 & -.03 & -.14 & $.22^{*}$ & $.27^{*}$ & - & & & & & & & \\
\hline 8. PTSD total & $-.23^{*}$ & .12 & -.02 & -.20 & -.01 & $.23^{*}$ & $.39 * *$ & - & & & & & & \\
\hline 9. HSCL Dep & $-.27^{*}$ & .02 & .07 & -.21 & .11 & $.22^{*}$ & .21 & $.68^{* *}$ & - & & & & & \\
\hline 10. HSCL Anx & -.21 & -.03 & -.06 & -.20 & -.07 & .15 & $.23^{*}$ & $.72^{* *}$ & $.75^{* *}$ & - & & & & \\
\hline 11. HSCL total & $-.25^{*}$ & .01 & .06 & -.21 & .08 & .21 & $.23^{*}$ & $.73^{* *}$ & $.96^{* *}$ & $.90 * *$ & - & & & \\
\hline 12. Sub WB (Aus) & .12 & -.02 & $.44^{* *}$ & $.26^{*}$ & $.46^{* *}$ & -.04 & .13 & $-.21 *$ & -.16 & -.13 & -.14 & - & & \\
\hline 13. Sub WB (Sud) & .15 & -.03 & $.49^{* *}$ & .12 & $.46^{* *}$ & .09 & .18 & -.06 & -.03 & -.10 & -.03 & $.74^{* *}$ & - & \\
\hline 14. Life Sat & .05 & -.15 & -.17 & $.21^{*}$ & .01 & -.12 & -.19 & $-.37^{* *}$ & $-.44^{* *}$ & $-.26^{*}$ & $-.40^{* *}$ & .08 & .05 & .41 ** \\
\hline
\end{tabular}


and years since arriving in Australia $(r=.462, p<.01)$. When controlling for these variables, separate regression analyses revealed that reported total close friends $(b=.217, t=2.549, p<.05)$, Australian acculturation $(b=1.146, t=2.70, p<.01)$, and multiculturalism $(b=.602, t=2.354, p<.05)$ were all significant predictors of subjective wellbeing as compared to the larger Australian community. Subjective wellbeing as compared to others in the Sudanese community in Australia was significantly correlated with education $(r=.493$, $p<.01)$, and years in Australia $(r=.458, p<.01)$. When controlling for these variables, total close friends $(b=.271, t=3.017, p<.01)$, Australian acculturation $(b=1.035, t=2.378, p<.05)$, and multiculturalism ( $b=.720, t=2.769, p<.01)$ were also significant predictors of subjective wellbeing as compared to others in the Sudanese community in Australia. Social ties and the ability to integrate into Australian culture were significant predictors of wellbeing within each the Sudanese and Australian communities.

Participants' overall Life Satisfaction scale $(0=$ very dissatisfied, 1 = somewhat dissatisfied, $2=$ neutral, $3=$ somewhat satisfied, $4=$ very satisfied) was created by averaging responses to the ten items, resulting in a mean score of $2.96(S D=0.54)$. Participants reported the lowest ratings of their current employment situation $(M=1.98, S D=1.30)$ and financial situation $(M=1.99$, $S D=1.15)$. Participants reported being most satisfied with their religion $(M=3.68, S D=0.70)$ and with their children if they were parents $(M=3.76, S D=0.75)$. However, it is important to note that these two items were non-normally distributed, with a large negative skew that indicates very few people endorsed dissatisfaction in these two life domains. The remaining items ranged between 2.80 (recreation and leisure) and 3.40 (health and health care) on the 0 - to 4-point scale.

Acculturation. Through categorical coding, the majority of participants ( $n=49,54.4 \%$ ) reported integration as their mode of acculturation. That is, they reported they identify with both Sudanese and Australian cultures. The next largest group $(n=36,40 \%)$ reported separation as their mode of acculturation (preference for only Sudanese culture). No participants reported marginalisation (low affiliation with both Sudanese and Australian cultures) and only one participant reported assimilation (preference for only Australian culture). Table 2 provides visual representation of the acculturation data. There were statistically significant differences between the two main groups and greater detail is provided in Table 5. Individuals endorsing integration reporting having been in Australia for longer periods of time $(t=17.81$; $p<.001)$, higher levels of education $(t=21.23 ; p<.001)$, and higher ratings of subjective wellbeing within the Sudanese $(t=14.39 ; p<.001)$ and Australian $(t=7.48$; $p<.01)$ communities. Further, individuals endorsing integration were more likely to be working $(t=20.38$; $p<.001)$ and report greater social connectivity within the Sudanese $(t=3.23 ; p<.05)$ and Australian $(t=5.20$; $p<.01)$ communities. There were no differences across the groups in reported levels of psychological distress, such as total PTSD and HSCL scores.

Participant ratings of preference for Sudanese and Australian cultures were not correlated with one another $(r=.066, n s)$. However, the number of years participants had spent in Australia was correlated with preference for Australian culture $(r=.590, p<.001)$ and not correlated with preference for Sudanese culture $(r=-.021, n s)$. In addition, age was not correlated with preference for Australian culture $(r=.056, n s)$ but was correlated with preference for Sudanese culture $(r=.317, p<.01)$ with older adults more likely to report identification with and knowledge of Sudanese culture.

Utilisation of services. Australia is renowned for having one of the most generous and comprehensive resettlement programs. On average, participants rated their overall satisfaction with the resettlement programs an average $3.70(S D=1.19)$ on a 5 -point Likert scale $(3=$ neutral, $4=$ somewhat satisfied $)$. Participants

\section{Table 5}

Comparison of Means for Integration versus Separation

\begin{tabular}{|c|c|c|c|c|c|}
\hline \multirow[t]{2}{*}{ Variable } & \multicolumn{2}{|c|}{ Integration $(n=49)$} & \multicolumn{2}{|c|}{ Separation $(n=36)$} & \multirow[t]{2}{*}{$\mathrm{F}$ ( $p$-value) } \\
\hline & Mean/Number & SD & Mean/Number & SD & \\
\hline Age & 34.80 & 10.36 & 33.37 & 7.92 & 1.36 (ns) \\
\hline Education & 4.53 & 1.56 & 2.33 & 1.51 & $21.23(p<.001)$ \\
\hline Years in Australia & 4.29 & 1.86 & 2.08 & 1.46 & $17.81(p<.001)$ \\
\hline Employment ( 1 = employed; $0=$ unemployed $)$ & .73 & .45 & .15 & .36 & $20.38(p<.001)$ \\
\hline Close Sudanese friends & 3.51 & .92 & 2.89 & 1.35 & $3.23(p<.05)$ \\
\hline Close Australian friends & 2.40 & 1.22 & 1.47 & 1.40 & $5.20(p<.01)$ \\
\hline Australian wellbeing & 4.63 & 2.57 & 2.64 & 2.06 & $7.48(p<.01)$ \\
\hline Sudanese wellbeing & 7.14 & 2.49 & 4.28 & 2.35 & $14.39(p<.001)$ \\
\hline PTSD symptoms & 1.64 & 0.52 & 1.53 & 0.54 & $2.25(n s)$ \\
\hline HSCL total score & 1.57 & 0.48 & 1.50 & 0.48 & $1.10(n s)$ \\
\hline
\end{tabular}


reported accessing an average $2.48(S D=1.10)$ services since arriving in Australia with the largest percentage of individuals accessing English language classes $(n=$ $79,87.8 \%)$, employment services $(n=54,60 \%)$, and housing assistance $(n=43,47.8 \%)$. In the current sample, 9 participants (10\%) reported accessing mental health services since arriving in Australia, as compared to $17 \%$ in a study of refugees from the former Yugoslavia in Brisbane (Markovic, Manderson, \& Kelaher, 2002). Individuals accessing more total services tended to have higher levels of prior trauma $(r=.280, p<.01)$, higher Australian acculturation scores $(r=.221, p<.05)$, and been in Australia for a longer period of time $(r=.245$, $p<.05)$.

Discrimination. Overall, participants reported varying experiences of discrimination in Australia, with onethird of the participants in the sample reported never experiencing any type of discrimination while living in Australia, and approximately one-third reporting regular experiences of discrimination. For example, significant numbers of people reported being treated with less courtesy $(n=16,32.6 \%)$, people acting like they are afraid of them $(n=13,25 \%)$, people acting like they are better than them $(n=15,28.4 \%)$, or being called names or insulted $(n=9,16.9 \%)$ at least a few times a month. Younger individuals $(r=-.226, p<.05)$ who had spent time in a refugee camp $(r=.356, p<.01)$ reported more frequent experiences of discrimination. Discrimination was not associated with key mental health outcome variables in the current study, and was not correlated with overall life satisfaction $(r=-.083, n s)$ or ratings of resettlement programs $(r=-.147, n s)$.

\section{Main Qualitative Findings}

The qualitative analyses utilise data from the semistructured qualitative interviews and describe participants': initial impressions of resettlement, negative influences on the resettlement experience, positive influences on the resettlement experience and definitions of 'the good life'. In each of these areas, key themes are explored and participant comments are employed to provide Sudanese descriptions of their experiences in being resettled in Australia.

Initial impressions of resettlement. Participants provided descriptions of their journeys to Australia and the initial reactions and experiences they had when first arriving. The participants reported widely varying levels of motivation and planning for their journeys which led them to Australia. Peter stated,

I hadn't thought about it, even hadn't thought I want to leave my country, but, but when everything just became very bad my parents said to me "it's not safe to stay here; you better go and leave the country and start a new life somewhere". And I found that very difficult.

Similarly, Rihab did not intend to end up in Australia.
I didn't decide to come to Australia when I decide to travel. I decide from my country to flee to Egypt an then I get stuck in Egypt for three years and a half when I applied for United Nation Commissioner for Refugees and I get granted the protection ... I'm very happy because I get granted the protection and get granted the resettlement in Australia. I'm happy to be in Australia. I came holding my dreams of improving myself and also working very hard to get good money and to have a good life in Australia and also to guarantee that I send money back to my parents and my sisters to help my mom and my dad.

Overall, participants reported feeling very welcomed when first arriving in Australia. Mary said,

... we were mostly welcome by the people who meet us on the airport, so we were really welcome. And then some people when we have the reception ... they were really welcome in the house, so we felt really welcome.

Jacob similarly stated,

Uh, luckily enough when we arrived here in Australia, we realized that people here are friendly, that was the first thing that really gave us good impression. We found that everyone is friendly, and everyone wants to help. And this for me was more than anything I was expecting.

They emphasised aspects of the initial resettlement program that provided a general orientation to life in Australia. John spoke of the importance of the initial orientation:

... there were a lot of things I had to go through, because I never know, I've never used a lift; I've never used things like a vending machine, using a tram. You know, using a bus and things were different for me. I don't know how to use ATM machines. You know, things like that were absolutely difficult for me. Seems simple but for me, it was really hard.

Deng expressed similar ideas,

I wouldn't talk because when I came to Brisbane it was very complex and I was asking, eh, will I really know these places, where it's really complicated to go around and see, and know couple of things that I never came across before. So it was really hard for me but fortunately some people who were there, people from migration office, they televise and show us some places and things that we did not.

Four of the participants were sponsored by friends to enter Australia and reported less interaction with the settlement organisations as their sponsors took on some of the responsibilities of the orientation. Amal, who was sponsored by a family friend, reported little contact with the resettlement agencies when arriving in Australia. She said, 'No, no organisation but only our friend who sponsored us, he did everything'. In 2007, this part of the program was being discussed for potential changes given the variability in services depending on the sponsor.

The importance of orientation and initial supports was influenced by previous exposure to western culture, which varied across participants. Alek said, 'To come to a new place is very difficult. Like me I cannot speak English [laughs]. It was very difficult for me'. Wal, on the other hand, reported the adjustment was not difficult for him. He said, 'I've been around, in Egypt and Nairobi 
and here, for me it is not a big change'. Fatima also reported prior exposure to western culture that influenced her experiences of the resettlement program,

Yes [resettlement program aid] was all helpful, but on the other hand it was all very humiliating in a way. But we were all very happy that we were alive, and we knew that it was this or probably being dead.

The differing levels of prior exposure to western systems influenced participants' reactions and attitudes toward the resettlement programs and were also highlighted when discussing negative influences in resettlement.

Negative influences in resettlement. Participants were asked to describe factors that had a negative impact on their resettlement experience. Four of ten participants cited the government resettlement programs as having a negative influence on their life in Australia, suggesting mixed feelings about the resettlement program as a whole. The individuals who reported negative experiences with the resettlement program also reported positive and supportive relationships with members of the Australian community and general feelings of being welcomed to Australia. This reflects the mixed emotions many have about the resettlement experience.

Participants reported they were dissatisfied with the generalised nature of the programs and the lack of cultural understanding by resettlement service providers and programs. Jacob said he believes the program funding is not effectively being used to help refugees:

Everything here is generalised as help. There is no specific help, or no specific idea that someone gives ... We have got, what Australia does is service providers here, lots of service providers everywhere. And the government is funding them. And the funds is, according to them and according to the programs that they put, is to help the refugees. We haven't realised this. We have realised that the funds they are asking for is to maintain their positions in their companies and to keep working. Because there was no sincere help that would be given to us, otherwise by now I would have gone back for my [professional] degree.

When asked to describe a negative influence on his resettlement experience, John said,

All the organisations funded by Immigration ... they aren't doing enough. That should at least be, you know, their focal point. They should at least voice out our interests, they should have set up our capacity and help us integrate and assist us as individuals.

He highlights his concern that providers are not assessing individuals' needs and providing the corresponding supports. Two other participants described specific aspects of the resettlement program, including lack of response from service providers regarding family concerns and problems with the healthcare systems. Alek said, 'They sent me to X [organisation] and then they say, ok, they gonna tell my problems to the people and they tell me the results. Until now I, since June [ 6 months prior], I haven't heard anything.
Another four of ten participants cited discrimination as being a significant negative influence on their experiences in Australia. This is comparable to the quantitative findings in which one-third of the sample reported regular experiences of discrimination. Further, although there was not a specific question regarding participants' experiences of discrimination, it was a topic that came up at some point during eight of the ten interviews. In particular, people talked about experiencing discrimination within the larger community, as related to the work environment and in trying to secure a job or housing. Peter, who identified the One Nation political party as having a negative impact on his resettlement experience, described differences in discrimination over time, as the Sudanese community has grown in the Brisbane area:

The biggest challenge I have found is like uh - because I'm uh, coloured, dark skin, everywhere you go people will be looking at you, or people will be pointing at you. And uh, because there wasn't many - actually, there wasn't many black people in Queensland ... And everywhere you go like uh, people will like - because you don't speak English, they think you are stupid. That's what people will think, they'll think you're stupid. You don't speak English, you're stupid. You have no idea, you don't know what to do. Yeah, and uh every girl like uh - people, they'll treat you like second class, all of that ... It's getting better, but there's some places you can't go.

Deng reported he applied to many jobs and not getting employment despite his qualifications:

I know that if I was an Australian actually I would get the job one or two, second to ten interview. But because of culture barrier that's why I couldn't get the Australians to accept me. So I knew, sometimes I could see there was a bit of discrimination, sometimes I could see. But I couldn't give up because I knew if I show them that I was desperate and something was going on I would destroy my way.

Participants described discrimination in hiring practices, difficulties on the job and concerns of underemployment. These challenges have also been described in another research study in Australia which examined employment difficulties among 'visibly different' refugee groups (Colic-Peisker \& Tilbury, 2007). African refugees appear to face particular challenges to securing employment, even those with higher levels of education.

Mary stated the negative stereotypes were a major factor for her in applying for a place to live:

For example, when we first came we were applying for the house and the lady ring to make our referral for that real estate and then said that they are not good tenancy, and then they told her that we burn, something, a cigarette in the house but when I went back to the migration, there was one lady she was a coordinator in the migration office, she's the one who give us that house, then I went back to her and I tell her that at the first time when we came to that house, there was a burn of a cigarette but none of us is a smoker, we never smoke, but they want to check our [unclear]. That I've always been thinking that, why these people treat us differently? And we treat the house we rent like our own house, if there is no other house there will be no place for us to sleep. So we treat that house like our own house because every- 
body use it you rent it and you like you own the house, you sleep there you are not living outside or homeless somewhere but you are renting. That what I was thinking is really so bad about this house. These people treat us like that, this is bad, it's bad all the time when I'm thinking about that.

In eight of the ten interviews the negative impact of discrimination was readily identified; however, two of the ten participants reported they had not experienced any forms of discrimination in Australia and two participants did not identify any negative influences in their resettlement experiences. The three participants who denied discrimination and/or negative influences were highly educated prior to arriving in Australia and are viewed as influential individuals in the Australian and Sudanese communities. Both the quantitative and qualitative data support variance in the experiences across members of the Sudanese community. Between 30 and $40 \%$ of participants across each methodology report discrimination as a serious concern and equal numbers of participants report it is not a problem at all.

Three participants also discussed the impact of community dialogue in 2007 following the public statements made by the Minister of Immigration calling to alter the composition of the humanitarian program due to the failure of specific refugee groups to integrate into Australian culture. The qualitative interviews were conducted between September and December 2007 with only three participants completing the interview prior to this event. The Minister's statements and ensuing public debate were readily discussed by participants, both on and off the record, despite there being no questions specifically addressing the topic.

Many Sudanese reported the events had a profound effect on their day-to-day lives. John stated:

Like nowadays I could see very prominent politicians like Kevin Andrews making a lot of comments judging Sudanese community not integrating very well into Australian society. And they don't - they just think that's mental, they don't understand we came primarily from a war-torn country and some people have gone through traumas and all that. And instead of appreciating and understanding where we came from - they should at least understand where we came from and what we are going through. And from this year you know, I'm not happy. I feel unwanted, unwelcome and that's been in Australia by comments that are made by young people and young persons ... I've been told that this society doesn't want me, because of comments made by a prominent person like Kevin Andrews.

Rihab stated that the comments have affected relationships within the Sudanese community, with recent arrivals reporting they received negative messages in Africa regarding the Sudanese-Australian community. She reported the negative stereotypes have come up in her work when welcoming new arrivals:

And now the Australian government is blaming the Sudanese that they didn't integrate, they did used to do bad things and this whole, these rumours, I don't know. But some Sudanese who have been accepted and coming from different places and I don't like to mention the name but I met someone who's coming from Africa with his family and then, I'm very happy when I find someone who can know and who I know I really like. Because I know my people they love tribes and all these things. I start showing him people from his own tribe, like just to make him feel safe and this is your people. And I realise that he say "No, I don't like any Sudanese people". I said "Why?" He said "Because in the orientation they gave us the Sudanese they are doing bad things and spoiling our reputation in Australia". I said "What? In the orientation?" And he said "Yes". And I never, I don't know if he's telling me the truth or not. They are getting orientated before coming to Australia to avoid Sudanese because they are criminals, and he said, "They spoil our reputation". And I say "What sort of criminals?" "Sometimes they jump you, sometimes they beat you and they do that", like he's repeating the things, they make it very difficult I said "No no no it's not like that". So, I show him what's really happening here because he became scared of his own community. And it's not like that. You know there is some negative points, but it is not very big.

Positive influences in resettlement. Participants were asked about positive influences in their process of resettlement. Four participants talked about specific people, such as their romantic partners or members of the Australian community as being significant sources of support in their lives and providing consolation and a 'very big push' (Jacob) when facing challenges in Australia. They described bonding capital and experiences of receiving emotional support and encouragement in establishing their new lives in Australia. Mary described gathering with others from the Sudanese community:

Yeah, like when I first came we met a group of Sudanese, we sometimes got a meeting, discuss about our life issues here in Australia and how we can help our people back there in a refugee camp ... Be together sometimes as a community, sharing life, forget about the difficulty, and thinking about the future ... That's what we did, to change the life a bit, so that you cannot thinking about the bad fact all the time, just think about the positive things so that you will change your life.

Four participants talked about specific Australians and community organisations that went out of their way to help address specific challenges. People reported receiving assistance at particular points in time that influenced their settlement trajectories. Three participants talked about assistance they received from people and organisations in applying for jobs and learning how to navigate the job market when first beginning to work in Brisbane. Amal described how she got a job with the help of two Australian friends:

When I applied to get a job at [an organisation], $\mathrm{X}$ and $\mathrm{Y}$ [two people] helped me, they organised a meeting with me and they helped me with how to do the interview. They asked me some questions for the interview, we did this more than three or four times, practising how can I do the interview.

Two other participants talked about community organisations that assisted with finding employment. Alek reported: 
I have got the people who are helping to me when I bring my forms for a course. I rang them and I say I want to do a course in nursing and they call me to do the interview and they help me to do the course, they pay me half of the money ... yeah they paid half of my course. And then even when I finish my course, and then they help me to do my resume and there is a lady in the course called X, they help me with resume and give me the list of nursing homes I will apply to. And then they do the resume and then probably I think 2 weeks I got my job.

Rihab said she got involved with an organisation on a volunteer basis and was then later able to obtain employment there:

Yes, an organisation that I work with, I volunteer, I start working with them as a volunteer, called the [community organisation]. And then after volunteering they start helping me, giving me some jobs ... There is a lady ... she is having very influence and ah, I am really inspired by how she help me a lot she introduce me to different organisations, she speak, she do believe in me, she's always encouraging me to do some study, she discover many skills for me that I don't know, so I really think she is very helpful to me.

Each of these participants highlights the importance of bridging capital and receiving instrumental support which helped them to obtain skills and jobs to better navigate their new environment.

One participant reported there were no positive influences on his resettlement experiences, because he came to Australia prior to the country establishing their current resettlement program. Another participant, Peter, stated religion and wisdom imparted by his parents had the most positive impact on him and helped him to adjust to his new home and cope with the challenges of resettlement. He said, 'It's my Christian life that's made me go through it; everything. Because, I don't think about tomorrow. Christ said, "Don't think about tomorrow, let tomorrow think for himself". Because, he don't know tomorrow'.

Definitions of the 'good life'. Participants were asked to describe their goals in resettlement and provide their beliefs about establishing a good life in Australia. Participants repeatedly emphasised social dimensions when defining 'the good life', with all but one of the participants highlighting the fundamental importance of social ties that underscore the collectivistic Sudanese culture. Likewise, this finding corresponds with the quantitative data in which having more close friends was linked to higher levels of subjective wellbeing and greater life satisfaction.

Rihab's statements convey the value of social connections and norms of reciprocity emphasised within the Sudanese community:

A good life is not just living for yourself because I do believe that if you have something to share you have to share it with friends or people from the community or helping other people. And when I talk about community, I talk too much about community, I didn't mean just my community, my Sudanese community, I mean like the whole world, the people that you know, and the people you can, they need your help, I mean you have to help them, either emotionally or financially, or giving yourself, everything, but I do believe if someone is very successful, he supposed to also have a good relationship with others in helping others because you are just not created for yourself. I am not created just for myself, I am created for help the community, the people that need me.

For many, the hopes and dreams for future generations frequently outweighed their own wants and needs. In particular, parents talked about their hopes for their children; a theme echoed throughout the immigration literature. Jacob said of him and his wife, '... we are content with what we have. And we are looking forward that our kids will achieve something better'. Amal expressed similar beliefs:

Really, I think of my kids, because my kids are my future. I hope to see them doing very excellent in their studies and I hope for next year and the year after for my son, to get a high degree and get to the university. And X (daughter) also.

She went on to define the good life:

I think to continue to work, to be close to my kids. To discuss about everything together, to share everything together. That's it [laughs].

Peter, who does not yet have children of his own, discussed his desire to start his own family in Australia and the opportunities that would be afforded to his children:

Seeing them [children] happy, and see them growing their life, and seeing it going smooth, without obstacle. That's going to be really very exciting. And uh, the choices they're going to make and they will dream for it, they will make it, it will happen for them. And uh, they will have clear goals set for themselves and they will achieve it without any uh, something stopping them. It's not like Sudan — with war, everything will stop. Disaster, everything will stop, yeah, I look forward for establishing my family.

Others talked about having positive relationships with family, friends and members of the community more generally. Mary said:

Yeah, the good life means being in a healthy, being in a healthy, wealthy, got some money, you enjoy your time with a different community ... If you sitting good places, have a fun day, being in a good kind of relationship, so being happy all the time, with your life, with yourself, with your community.

Rihab agreed:

For me, the happiness and the definition of a good life is that you having a good person, like you are caring of each other, either a boyfriend or a husband or a friend or a family member, at least you have someone that is caring for you and you are caring for him or for her. This is the definition of a good life. The definition of a good life also is if you are having a good job, and you are happy and interested in this job. Apart for me, whether you get a lot of money or you get one dollar or two dollars, it doesn't matter; the most important thing for me is that if I get a good job, in a place that I really love it and enjoy it ...

Wal emphasised the importance of social interactions with others and the importance of crosscultural understanding and discourse: 
It's good now, I'm happy, we are talking together. I think this is what makes you happy. Have friendship with people, sharing ideas, plan for the better, have harmony. You know, and see, happy to see your friends achieving her goals or his goals. And, most of the areas. Maybe happy to be at peace, peace with each other.

One individual reported her goals in resettlement included being accepted as an Australian and to be able to put the past behind her. In defining 'the good life' Fatima said,

Being accepted as an Australian. Not continually having to say where I'm from. I know lots of people are asking just out of sheer curiosity, because they want to learn about things that they haven't been through. And it's not a question aimed in any way at putting you down. But, for me right now, it doesn't really matter. People ask me and I tell them where I'm from; I want to. But for people who arrive here new, and they want to belong - mind you, they have to want to belong. Because lots of those people who are here don't want to belong here. This is like a train station, and they're on the way somewhere, back preferably, forward, or whatever. But this is just a train station. For me, it's not a train station; it is my home, and I want to stay. So, being accepted as an Australian is was the most important thing.

Fatima describes ways in which she feels singled out as an outsider and the differences within the community in motivation and desire to establish a new life as an Australian. She recognises that some individuals view resettlement as a temporary means of safety with more long-term goals of returning to their homeland when the opportunity arises. But for those establishing roots, like Fatima, the importance of a sense of acceptance and belonging seems paramount.

Fatima reported another aspect of achieving 'the good life' is to be able to put the past behind her:

I'm putting my past behind me, trying to forget all, you know - basically not having the past make me what I am now. I know it is very difficult, but I don't want to be - to have the buttons pushed in me about what happened in the past. I don't want to have to jump every time a military craft flies over. I don't want to jump when I'm at fireworks, 'cause I'm hearing explosions again. I don't want to fear an approaching policeman; they're not going to do anything here to me. To dread I was probably going to be arrested again ... I want that to stop, that would be a good life.

\section{Discussion}

The current findings highlight the complexities of the resettlement experience for people from Sudan and the range of positive and negative influences in establishing a new life in Australia. Approximately one-quarter of the sample reported significant psychological distress, which is similar to rates of symptomatology reported in other studies (e.g., Lie, 2002; Schweitzer et al., 2006). Individuals with higher levels of psychological distress tended to be younger, have experienced higher levels of trauma and to have spent time in a refugee camp. Findings support previous literature suggesting that with higher levels of prior trauma there are increased symp- toms of psychological distress. The experiences of past torture and trauma, although experienced to varying degrees among this sample and across refugee cohorts, are inherent to the refugee experience.

However, there are unique challenges faced by the Sudanese community and among specific groups of Sudanese-Australians; in particular, younger adults and those who spent time in a refugee camp. Higher levels of distress among these two groups may be related to some of the specific challenges that they face, including experiences of discrimination. There was significant variability in reports of discrimination, with one-third of the sample never experiencing discrimination in Australia and onethird reporting frequent experiences of discrimination. In both the quantitative and qualitative data, younger adults were more likely to report experiences of discrimination through employment practices and in their everyday interactions with others in Australia. The reports of discrimination in this study correspond with other research examining Australian prejudicial attitudes (Schweitzer, Perkoulidis, Krome, Ludlow, \& Ryan, 2005) and the particular challenges of Sudanese-Australian youth documented in research by the Victorian Equal Opportunities and Human Rights Commission (VEOHRC, 2008). Schweitzer and colleagues (2005) found that perceived threats by refugee groups was a significant predictor of prejudicial attitudes within an Australian university student sample, in which over half the sample reported above the midpoint scores in prejudicial attitudes toward refugees. In the current study, employment was identified as a key area of dissatisfaction in the quantitative and qualitative data with participants readily identifying experiences of discrimination and barriers to securing employment. The perceived threats by refugees for jobs and other resources may be a driving force in the Sudanese experiences of discrimination reported here; however, they could not be directly explored with the data obtained in the current study.

Furthermore, the sociopolitical events of 2007 had a significant impact on the Sudanese community. Although not specifically queried within the measures, the events were spontaneously brought up by the majority of individuals who participated after the public announcement was made to reduce the African resettlement program. The current empirical findings suggest that the majority of Sudanese are endorsing the primary markers of integration. There were differences between participants who endorsed integration versus separation, although none of the primary outcomes such as psychological distress varied across the two groups. In particular, participants endorsing integration had been in Australia an average 2.2 years longer than individuals who endorsed separation as their mode of acculturation; suggesting it takes time to establish a new life, learn a new culture and language, and grieve the loss of one's homeland and way of life. Unfortunately, there is a dearth of longitudinal data that 
would allow for greater understanding of the mechanisms of the process of acculturation.

The current findings underscore the relation between social connectedness and wellbeing within the Sudanese community. The foundational importance of social ties within Sudanese culture, as well as other collectivistic cultures, has been highlighted in other literature (e.g., Bracken, 2002; Tankik \& Richters, 2006) and both the quantitative and qualitative data underscore the importance of social ties and social support when defining aspects of 'the good life' and self-ratings of wellbeing within each the Sudanese and larger Australian communities. Qualitative participants emphasised the importance of both bonding and bridging capital as having positive influences on their resettlement experience and the quantitative data reveal that social connectivity, with both Sudanese and Australians, are predictors of perceived wellbeing and status within the community.

There was a significant loss in perceived subjective wellbeing when participants compared themselves to the larger Australian community as opposed to the Sudanese community. This may be linked to the internal drive and motivation for self-sufficiency, which was identified by the participants. They reported a desire to improve one's life for the sake of themselves, their family and their community and spoke of the importance of opportunities for advancement, such as through work and education. As one qualitative participant stated, people want to 'carry their own cross'. Resettlement programs would benefit from continuing to build upon work by Paulo Friere. He states in Pedagogy of the Oppressed that 'the pedagogy of the oppressed, a pedagogy which must be forged with, not for, the oppressed (whether individuals or peoples) in the incessant struggle to regain their humanity' (2000, p. 48). People want to care for themselves and their families and desire the skills and the opportunities to do so.

\section{Limitations}

The current study has several limitations, in particular the challenge of conducting crosscultural research that adequately captures the experience of the Sudanese community. Due to financial limitations of the current project, many of the procedures were not up to gold standards for crosscultural research, such as the translation and back-translation of all study materials and the use of measures developed and validated with the target population (Brislin, Lonner, \& Thorndike, 1973). Although some of the measures used have been developed with other refugee populations, there are concerns related to the psychometric fit of scales not developed and validated for Sudanese populations and the current sample is not of sufficient size to run such analyses.

In addition, random sampling strategies were not used in either the quantitative and qualitative segments of the study, which is a common concern throughout the refugee literature. The quantitative sample is similar to
Queensland resettlement data in regard to age and level of education; however, the study oversampled females and people who identified as Muslim as compared to Queensland resettlement data (DIAC, 2007b). The qualitative participants reported higher levels of education and having been in Australia for a longer period of time and therefore are not representative of the quantitative sample or the Sudanese community as a whole.

Longitudinal enquiry, absent in the current project and lacking in the field as a whole, would provide an opportunity to examine the processes of change and the dynamic process of acculturation. Cross-sectional data provides understanding of the relations between variables but cannot be used to make statements about causality. Longitudinal data would provide the opportunity to examine ways in which the challenges of resettlement are effectively addressed through individual and community healing processes with the support of settlement programs.

\section{Conclusions}

Refugee resettlement poses significant challenges for both the migrating and host communities. People from a refugee background must cope with past trauma and losses and begin to adapt to an entirely different culture, community and way of life. This is a process that requires time, energy, determination and culturally appropriate supports. Host communities too must adapt to the new cultures, customs and challenges of working with diverse refugee groups. The entire resettlement experience demands collaboration and mutual respect between individuals from a refugee background and members of the host community. Australia resettles more individuals per capita and provides more extensive funding and services to newcomers than other resettlement programs. However, it is a country - alongside many others - that continues to struggle with public debates over immigration and multicultural policies. These issues clearly influence newcomers' experiences.

Governments, communities and individuals on each side of the refugee experience struggle over the shortand long-term challenges of forced migration. In particular, these challenges can be compounded by economic challenges and perceived threats by newcomers to valuable resources (Espenshade \& Belanger, 1998). The experiences of Sudanese in Brisbane, Australia in 2007 are unique, yet bring to light some of the overarching concerns of interracial relations, debates over acculturation and the ways in which refugee perspectives and experiences may be different from those of their host community. 'We exist in a social world: our being, our identity and self-understanding, is always bound up with other people' (Bracken, 2002, p. 131), and the experiences of Sudanese in the current study were clearly affected by the sociopolitical context and their interactions with others in Australia. Ongoing global migration, 
both forced and voluntary, demands better understanding of the impacts and processes of crosscultural contact and to foster optimal outcomes for migrants and host communities (Castro \& Murray, 2009). Only by discussing and examining the totality of the refugee and host experiences can we improve upon current practices, join in our common humanity and improve the quality of life of all people.

\section{Acknowledgement}

This document is based upon data gathered for my doctoral dissertation, chaired by Alex Zautra, $\mathrm{PhD}$ while the author was affiliated with the Psychology Department at Arizona State University and as a Fulbright Fellow at the Boilerhouse Community Engagement Centre at the University of Queensland. I thank the members of the Sudanese community who participated, as well as Sana Mohamed, Khadiga Mohamed, Abraham Aleer, Sue Scull, Anna Wiederroth, Brian Wickhem and Dawn Noggle who consulted and assisted with the research. The research was supported by the Fulbright Association, the Health Psychology Division of the American Psychological Association and National Cancer Institute Grants \#U54 CA132384 and \#U54 CA132379.

\section{References}

Adler, N.E., Epel, E.S., Castellazzo, G., \& Ickovics, J.R. (2000). Relationship of subjective and objective social status with psychological and physiological functioning: Preliminary data in healthy white women. Health Psychology, 19, 586-592.

Ager, A., \& Strang, A. (2008). Understanding integration: A conceptual framework. Journal of Refugee Studies, 21, 166-191.

Berry, J. (1994). An ecological perspective on cultural and ethnic psychology. In E.J. Trickett, R.J. Watts \& D. Birman (Eds.), Human diversity: Perspectives on people in context (pp. 115-141). San Francisco: Jossey-Bass.

Bracken, P.J. (2002). Trauma: Culture, meaning and philosophy. London: Whurr Publishers Ltd.

Brislin, R.W., Lonner, W., \& Thorndike, R.M. (1973). Crosscultural research methods. New York: John Wiley \& Sons.

Browne, P. (2007, October 5). Refugees: Back to the future. Australian Policy Online. Retrieved March 29, 2009, from http://www.apo.org.au/webboard/comment_results.chtml? filename_num $=176779$

Carlson, E.B., \& Rosser-Hogan, R. (1991). Trauma experiences, posttraumatic stress, dissociation, and depression in Cambodian refugees. American Journal of Psychiatry, 148, 1548-1551.

Castro, F.G., \& Murray, K.E. (2009). Cultural adaptation and resilience: Controversies, issues and emerging models. In J.R. Reich, A.J. Zautra, \& J.S. Hall (Eds). Handbook of Adult Resilience (pp. 375-403). New York: Guilford.

Colic-Peisker, V., \& Tilbury, F. (2007). Integration into the Australian labour market: The experience of three 'visibly different' groups of recently arrived refugees. International Migration, 45, 59-83.
Davidson, G.R., Murray, K.E., \& Schweitzer, R.D. (2008). Review of refugee mental health and wellbeing: Australian perspectives. Australian Psychologist, 43, 160-174.

Department of Immigration and Citizenship. (2007a). Sudanese community profile. Retrieved July 29, 2009, from http://www.immi.gov.au/living-in-australia/deliveringassistance/government-programs/settlement-planning/ _pdf/community-profile-sudan.pdf

Department of Immigration and Citizenship. (2007b). Settlement Reports. Retrieved January 25, 2009, from http://www.settlement.immi.gov.au/settlement/enterSelect Report.do

Espenshade, T.J., \& Belanger, M. (1998). Immigration and public opinion. In M.M. Suarez-Orozco (Ed.), Crossings: Mexican immigration in interdisciplinary perspectives (pp. 364-403). Cambridge, MA: Harvard University Press.

Essed, P. (1991). Understanding everyday racism. Newbury Park, CA: Sage.

Freire, P. (2000). Pedagogy of the oppressed (30th anniversary ed.). New York: Continuum International Publishing Group.

Gorman, R.F. (1991). U.S. overseas refugee assistance. In H. Adelman (Ed.), Refugee policy: Canada and the United States (pp. 118-142). Toronto: York Lanes Press.

Hart, C., \& Maiden, S. (2007, October 6). Race to point finger of blame. The Australian. Retrieved August 30, 2009, from http://www.theaustralian.news.com.au/

Huberman, A.M., \& Miles, M.B. (1994). Data management and analysis methods. In N. Denzin \& Y. Lincoln (Eds.), Handbook of qualitative methods. Thousand Oaks, CA: Sage.

Kinzie, J.D., Boehnlein, J.K., Leung, P.K., Moore, L.J., Riley, C., \& Smith, D. (1990). The prevalence of posttraumatic stress disorder and its clinical significance among Southeast Asian refugees. American Journal of Psychiatry, 147, 913-917.

Kvale, S. (1996). InterViews: An introduction to qualitative research interviewing. Thousand Oaks, CA: Sage.

Lie, B. (2002). A 3-year follow-up study of psychosocial functioning and general symptoms in settled refugees. Acta Psychiatrica Scandinavica, 106, 415-425.

Markovic, M., Manderson, L., \& Kelaher, M. (2002). The health of immigrant women: Queensland women from the former Yugoslavia. Journal of Immigrant Health, 4, 5-15.

Marsella, A.J., Bornemann, T., Ekblad, S., \& Orley, J. (1994). Amidst peril and pain: The mental health and wellbeing of the world's refugees. Washington, D.C.: American Psychological Association.

McAdams, D. (2006). The redemptive self: Stories Americans live by. New York: Oxford University Press.

McDougall, B. (1991). Notes on Canadian refugee policy. In H. Adelman (Ed.), Refugee policy: Canada and the United States (pp. 2-10). Toronto: York Lanes Press.

Metz, H.C. (1991). Sudan. A country study. Washington, DC: GPO for the Library of Congress.

Miles, M.B., \& Huberman, A.M. (1994). Qualitative data analysis: An expanded sourcebook (2nd ed.). Thousand Oaks, CA: Sage.

Mollica, R.F., Wyshak, G., de Marneffe, D., Khuon, F., \& Lavelle, J. (1987). Indochinese versions of the Hopkins Symptom 
Checklist-25: A screening instrument for the psychiatric care of refugees. American Journal of Psychiatry, 144, 497-500.

Morrow, S.L., \& Smith, M.L. (2000). Qualitative research for counseling psychology. In S.D. Brown \& R.W. Lent (Eds.), Handbook of counseling psychology (3rd ed., pp. 199-230). Hoboken, NJ: John Wiley \& Sons.

Paardekooper, B., deJong, J.T.V.M., \& Hermanns, J.M.A. (1999). The psychological impact of war and the refugee situation on South Sudanese children in refugee camps in Northern Uganda: An exploratory study. Journal of Child Psychology and Psychiatry, 40, 529-536.

Putnam, R.D. (2000). Bowling alone: The collapse and revival of the American community. New York: Simon and Schuster.

Rudmin, F.W. (2006). Debate in science: The case of acculturation [Electronic Version]. AnthroGlobe Journal. Retrieved July 6, 2008, from http://malinowski.kent.ac.uk/docs/ rudminf_acculturation_061204.pdf

Schweitzer, R., Greenslade, J., \& Kagee, A. (2007). Coping and resilience in refugees from the Sudan: A narrative account. Australian and New Zealand Journal of Psychiatry, 41, 282-288.

Schweitzer, R., Melville, F., Steel, Z., \& Lacherez, P. (2006). Trauma, post-migration living difficulties, and social support as predictors of psychological adjustment in resettled Sudanese refugees. Australian and New Zealand Journal of Psychiatry, 40, 179-187.

Schweitzer, R., Perkoulidis, S. A., Krome, S. L., Ludlow, C. N., \& Ryan, M. (2005). Attitudes towards refugees: The dark side of prejudice in Australia. Australian Journal of Psychology, 57, 170-179.
Simich, L., Hamilton, H., \& Baya, B.K. (2006). Mental distress, economic hardship and expectations of life in Canada among Sudanese newcomers. Transcultural Psychiatry, 43, 418-444.

Tankik, M., \& Richters, A. (2006). Silence as coping strategy: The case of refugee women in the Netherlands from SouthSudan who experienced sexual violence in the context of war. In B. Drozdek \& J.P. Wilson (Eds.), Voices of trauma: Treating psychological trauma across cultures. Elk Grove Village, IL; Springer.

Tempany, M. (2009). What research tells us about the mental health and psychosocial wellbeing of Sudanese refugees: A literature review. Transcultural Psychiatry, 46, 300-315.

United Nations High Commissioner for Refugees. (2003). Framework for durable solutions for refugees and persons of concern. Geneva: Author.

United Nations High Commissioner for Refugees. (2007). UNHCR Global Report 2007-Sudan. Geneva: Author.

United Nations High Commissioner for Refugees. (2008a). 2007 global trends: Refugees, asylum-seekers, returnees, internally displaced and stateless persons. Geneva: Author.

United Nations High Commissioner for Refugees. (2008b). Protecting refugees and the role of UNHCR. Geneva: Author.

Victorian Equal Opportunity \& Human Rights Commission. (2008). Rights of passage: The experiences of AustralianSudanese young people. Melbourne, Australia: Author.

Zea, M.C., Asner-Self, K.K., Birman, D., \& Buki, L.P. (2003). The abbreviated multidimensional acculturation scale: empirical validation with two Latino/Latina samples. Cultural Diversity \& Ethnic Minority Psychology, 9, 107-126. 